\title{
Beyond humanitarian aid: Connecting the dots with development
}

\author{
Cyprien Fabre
}

OECD Development Co-operation Directorate

\begin{abstract}
Drought, floods, earthquakes, conflict, climate change: these are just some of the areas which humanitarian assistance is traditionally called on to address. Policymakers tend to consider short-term humanitarian assistance and longer-term development assistance quite separately, yet they are two sides of the same coin.
\end{abstract}

Development cooperation is a form of relation between countries rooted essentially in the wave of independence in the 60's. In its most traditional and historical form, development cooperation aims at supporting countries in their economic development and poverty reduction. Those objectives are long-term endeavours crossing many sectors, as exemplified by the 17 Sustainable Development Goals. ${ }^{1}$ In some countries - not necessarily the poorest - the societal, political, or even environmental equilibrium are more fragile than in others. When that equilibrium are disrupted, plunging countries into crises, the most vulnerable people cannot always cope even to meet their basic needs, and those needs can exceed the capacity - or the willingness - of the affected state to meet those needs. In such situations, humanitarian aid is proposed as a solution to cover some of the most urgent needs: shelter, food, water. Soon after the crisis is over, when the government is able and willing to cover its population's basic needs, and livelihood opportunities are restored, humanitarian aid usually cease. It's time for recovery action through political, economic and social measures.

This simple model is easy to understand, but it does not work. Today's crises and conflicts are more complex than in the past, especially in Middle-Income countries like in Syria or Libya where a complex interaction of root causes intertwines. They last longer, generate massive population displacement and do not develop in linear ways. Gone are the days where crises were seen as accident on the development path, to be cleared up with humanitarian assistance. As a result, the need for emergency assistance is increasingly overlapping with long-term development needs: there is no longer a specific point in time when people's needs cease to be "humanitarian" and instead become linked to "development".

The occurrence of humanitarian needs is often a direct reflection of the most serious development challenges or political crises. As a result, humanitarian aid may not necessarily be the best and certainly not the sole instrument to meet people's needs in crisis contexts.

\footnotetext{
${ }^{1}$ About the Sustainable Development Goals, see https://www.undp.org/content/undp/en/home/sustainable-development-goals.html.
} 
Despite this, the current international system relies heavily on the provision of short-term, emergency humanitarian aid whenever a crisis occurs (OECD, 2019a).

For example, 11,7 million people are in need of some form of assistance within Syria, according to the UN. ${ }^{2}$ In spite of a receding in overall insecurity, food prices have increased in Syria Arab Republic notably as a result of limited access to land and inputs, reduced local production, damage and looting of production assets and processing plants. As a result, most vulnerable households adopt negative coping mechanisms to meet food shortages: reliance on less preferred and less expensive food, or reduced number of meals. 3 Responding to this situation requires a blend of emergency measures and long-term food security programme. It also requires to listen to what people need, and how the perceive the aid the get.

Together with its partner, Ground Truth Solutions, the OECD interviewed over 12,000 people either affected by crises or working as humanitarian field workers between 2016 and 2019. Respondents were interviewed about their perceptions in seven different country presenting different crises patterns, namely in Lebanon Haiti, Iraq, Somalia, Afghanistan, Uganda and Bangladesh (OECD, 2018).

Primarily, the interviews highlighted that humanitarian assistance represents only a part of what individuals require. People affected by crises cannot live exclusively on humanitarian assistance; it is insufficient to cover their basic needs. After the initial emergency phase, they generally need to find other sources of income, a livelihood, or otherwise resort to other measures, such as leaving school or accruing debt.

Figure 1 - Perception about humanitarian assistance in Lebanon, 2018.

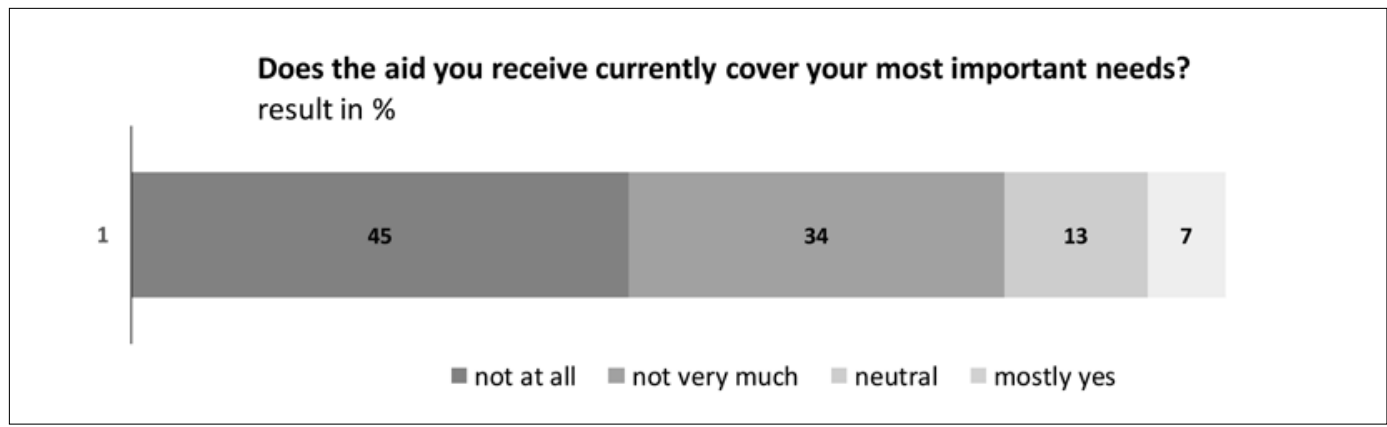

If humanitarian assistance is not sufficient to meet people's core needs, it is even less effective in helping people achieve economic self-sufficiency. People in crisis contexts surveyed by the OECD and Ground Truth Solutions consistently mentioned their lack of economic and livelihood opportunities as a primary grievance. In the protracted crises that make up most humanitarian contexts, affected people want financial autonomy, not prolonged assistance. People in crisis contexts want to work, for their dignity and well-being. Humanitarian assistance is not designed to put an end to need, but to sustain people through times of need. In addition, humanitarian aid is often unpredictable in nature. Longer-term

\footnotetext{
22019 Humanitarian need overview, Syria, https://hno-syria.org/.

32019 FAO/WFP crop and food security assessment mission to the Syrian Arab Republic, https:/fscluster.org/ sites/default/files/documents/cfsam_2019.pdf.
} 
Figure 2 - Humanitarian workers' perception about fairness of aid in Lebanon, 2018.

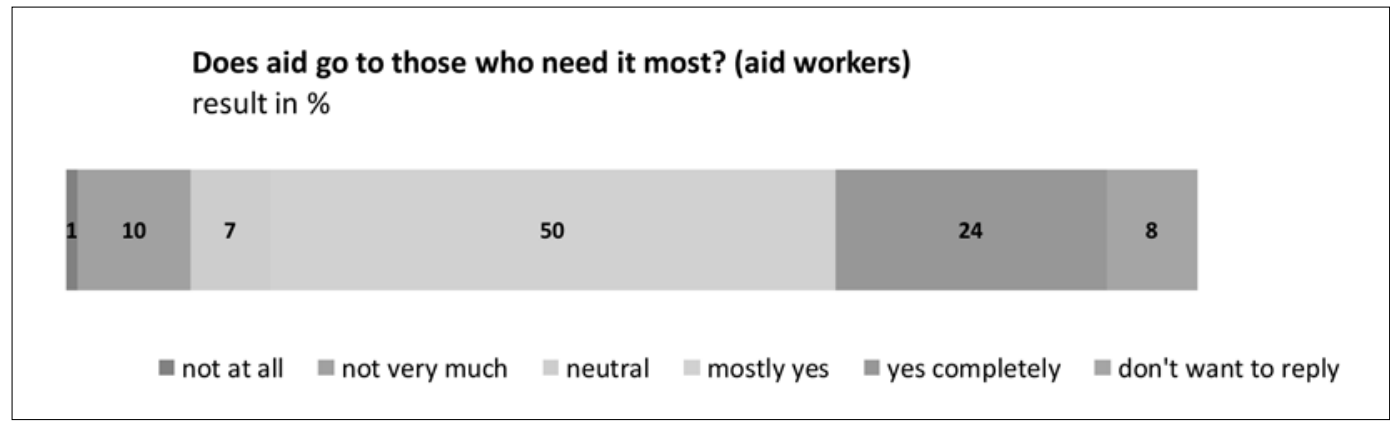

Figure 3 - Beneficiaries' perception about fairness of aid in Lebanon, 2018.

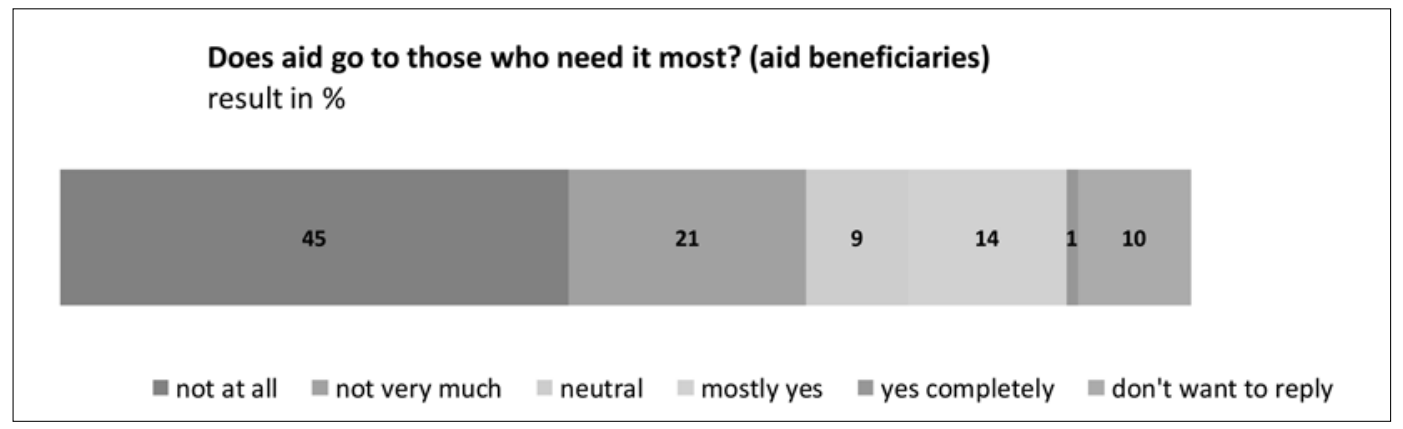

approaches should be mobilised in order to enable an environment in which people affected by crises are able to earn a living.

The project also showed a remarkable difference between aid recipients and humanitarian aid workers over their perceptions of whether or not aid was fairly distributed. Humanitarian workers were confident that aid was going to those who need it most (Figure 2). In stark contrast, aid recipients responded that it was not (Figure 3). They argued that people lacking political or social power, including those with illnesses, the elderly, and remote and undocumented individuals, do not always receive the aid they need.

What it means is that humanitarian aid respond to people's needs as long as those needs fit into the strict humanitarian sectors of strictly mandated organisations. However, vulnerability goes beyond those siloes, especially in protracted crises where displaced people live alongside a vulnerable local population. In such crises, people' needs have to be seen in a broader way, not only taking into account the gaps to fill, but people's aspiration to be autonomous.

Donors chose to engage resources in a crisis abroad because it is their interest to do so. It demands that we consider carefully how we define a crisis in the first place. For instance, although both political crises and natural disasters can create humanitarian needs, labelling all crises as "humanitarian crises" does not incite decision-makers to engage with anything other than humanitarian assistance. Countries have a range of instruments at their disposal that include, but are not limited to, humanitarian assistance. They also need to mobilise development and peace assistance, and use levers such as political dialogue, multilateralism, 
peacebuilding or stabilisation measures when relevant, and engage the private sector too when necessary. The difficulty is that players operating in these areas must work coherently in order to be most effective. This coherence is often referred to as "the Nexus" in development and humanitarian circles.

However, the way donors operate, the administrative processes in place, and aversion to engaging public money in risky contexts all make it hard to marshal resources for anything other than short-term humanitarian budgets delivered through big, trusted humanitarian partners with both expertise and absorption capacity. Overcoming these stubborn divides is a challenge. To help its member, the OECD Development Assistance Committee adopted earlier in 2019 a recommendation to frame what it means for a donor to engage coherency in fragile and crises contexts (OECD, 2019b). Clearly, we must enable all partners to define, in each crisis context and at different points in time, the tools that are best for the problem at hand and how best to wield them together.

Humanitarian assistance works as a temporary painkiller, but cannot treat the underlying cause. To work properly, humanitarian policy responses should by default be part of a broader, collaborative plan, using the humanitarian-development-peace nexus.

\section{References}

OECD, 2018. Humanitarian survey, https:/www.oecd.org/dac/conflict-fragility-resilience/humanitarian-financing/humanitarian-surveys.htm.

OECD, 2019a. Lives in Crises: What Do People Tell Us About the Humanitarian Aid They Receive?. Paris: OECD Publishing, https://doi.org/10.1787/9d39623d-en.

OECD, 2019b. DAC Recommendation on the Humanitarian-Development-Peace Nexus, OECD Legal Instruments. OECD, Paris, https://legalinstruments.oecd.org/en/instruments/OECD-LEGAL-5019. 